\title{
Middle School Students' Motivation in Solving Modelling Activities With Technology
}

\author{
Wajeeh Daher ${ }^{1,2^{*}}$ \\ ${ }^{1}$ Al-Qasemi Academic College of Education, ISRAEL \\ ${ }^{2}$ An-Najah National University, PALESTINE
}

Received 2 June 2021 - Accepted 26 July 2021

\begin{abstract}
Researchers pointed at modelling activities as affecting positively students' learning including motivation to learn, but little research has studied students' motivation to learn mathematics during their engagement in modelling activities with technology. Three groups of 4-5 students carried out the Roc modelling activity utilizing the internet and GeoGebra. The data was collected using video recording and students' solution texts. Inductive and deductive content analysis were used to analyze the data. The research results indicated that the groups experienced motivational patterns that included both sympathy and mastery styles, where these styles were accompanied with confirming styles in general, but sometimes with rebellious styles too. In addition, carrying out the modelling activity using the internet and GeoGebra, the group members were engaged primarily with processes-based motivational styles, but doing so, they kept in mind their goal to build a mathematical model of the Roc bird.
\end{abstract}

Keywords: GeoGebra, mathematical activity, middle school, modelling activity, motivation, technology

\section{INTRODUCTION}

Mathematical modelling is a context in which students perform activities similar to those encountered in real life, which prepares them to be successful in real life tasks (Bora \& Ahmed, 2019). These activities constitute a context in which students could engage in cognitive and metacognitive processes (Shahbari, Daher, \& Rasslan, 2014) and nourish their social positions and emotions (Daher, 2015). So, modelling activities are considered as rich experience for monitoring changes in both cognitive and affective domains (Shahbari, Tabach, \& Heyd-Metzuyanim, 2019). Because alongside the constructing of models and the mathematical development, the participants have opportunities for social development, because they need to develop their argumentation skills while they assume, explain, and justify for each other (English, 2003). Researchers pointed at mathematical modelling as increasing students' motivation to learn mathematics (e.g., Arseven, 2015; Blum, 1995), but little research has verified this issue empirically. The present research attempts to shed light on this issue.
Motivation, its meanings, the factors that influence it and its impact attract the attention of educational researchers (e.g., Bal-Taştan et al., 2028; Daher, Alfahel, \& Anabousy, 2021; Ntourou, Kalogiannakis, \& Psycharis, 2021). Deci and Ryan (2000, p. 54) say that "To be motivated means to be moved to do something". Bomia et al. $(1997$, p. 1) say that motivation refers to "a student's willingness, need, desire and compulsion to participate in, and be successful in the learning process". Middleton and Spanias (1999) viewed motivation as reasons behind the individual's behaving in a given situation.

Factors that influence motivation to learn could be the success experienced learning (Middleton \& Spanias, 1999), teacher's supportiveness and classroom environment (Middleton \& Spanias, 1999). Jang (2008) argues that to facilitate students' motivation, two effects should be attended to: students need to see the importance and personal utility within the task, and they need to experience high autonomy during the task. These two factors could be satisfied in carrying out modelling activities that are related to students' life on

(c) 2021 by the authors; licensee Modestum. This article is an open access article distributed under the terms and conditions of the Creative Commons Attribution License (http://creativecommons.org/licenses/by/4.0/). 


\section{Contribution to the literature}

- The study attempts to study motivational styles and patterns in the mathematics classroom.

- The study uses observations in the mathematics classroom and students' texts to study motivation for learning mathematics.

- The study analyses students' motivation in the mathematics classroom in technology-rich modelling activities.

one hand and encourage students' freedom to take decisions on the other hand (Mousoulides, Christou, \& Sriraman, 2008; Shahbari \& Peled, 2017). In the present research, we consider students' motivation during the carrying out of a modelling activity in which students are engaged in investigation of a huge bird called Roc. This is a legendary bird reported to have enormous dimensions.

\section{The Role of Technology in Mathematical Modelling}

Technology enriches modelling contexts through using various tools. Mousoulides et al. (2007) found that the learning environment based both on the software on the activity helped students realize and to get familiar with the activity, which enhanced their explorations and mathematical understandings. Using technology through engagement with modeling activities contributes to increased learning and interaction between learners (Geiger, Faragher, \& Goos, 2010). Arzarello, Ferrara, and Robutti (2012) found that the dynamic features of technology support students in their writing of conjectures, and the validation or refutation of these conjectures, along with the decision upon the independent and dependent variables. Daher and Shahbari (2015) found that the spreadsheets helped prospective teachers build the technological mathematical model, where the integration of the spreadsheets happened in different phases of building the model.

Molina-Toro, Rendón-Mesa, and Villa-Ochoa (2019), by reviewing the literature on the role of technology in mathematical modelling, found that the literature pointed at technology support of the various modelling processes that constituted part of the modeling cycle. The reviewed literature suggested that there are two roles of technology in carrying out modelling activities in the classroom. The first role is technology as a resource in modeling processes, where this resource enables the participants to transform their actions and change their analysis of the mathematical situation. The second role is technology as reorganizing the dynamics of the modeling processes. In this role, technology served the development of the modelling process. The present research reports students' motivational styles when they are engaged with modelling processes when they base their processes on using the Internet and GeoGebra.

\section{THEORETICAL FRAMEWORKS}

In the present research, we will use two theoretical frameworks. The first theoretical framework is concerned with mathematical modelling with technology, while the second theoretical framework is concerned with motivation, where we are concerned in the present research with motivation in the classroom.

\section{Mathematical Modelling with Technology}

There are different views about the level and the way of technology integration when engaging in modeling activities; such as Siller and Greefrath (2010) who indicate that technology integration happens after constructing the mathematical model. while Daher and Shahbari (2015) reported that there is more than one single model. Specifically, Daher and Shahbari (2015) found that the technology-based modelling processes of the participating groups were: Taking decisions regarding the characteristics of the technological environment to be built with the specific technological tool in order to build the technological mathematical model, discussing performing mathematical actions in the technological environment, taking management decisions that fit the technological environment, building the model in the technological environment, and validating the technological mathematical model with real examples.

\section{Reversal Theory of Motivation}

Reversal theory suggests that four domains of experience are essential aspects of normal subjective experience, where each one is always necessarily present to some degree in our awareness. The first domain is Telic and Paratelec, which relates to means-and-ends; i.e., consciousness of what we are doing and why. This could be either the goal of the activity (telic state) or the activity itself (paratelic state). Apter $(2005$, p. 8$)$ says that "the telic state may be said to embody the value of achievement, while the paratelic state embodies that of enjoyment". In the present research, we consider the 'product' as fitting the style related to the Telic state instead of 'serious' used by Apter (2005). In addition, we consider the 'process' for the style related to the Paratelic state instead of 'playful' used by Apter (2005). Doing that, we depended on the description of Telic and Paratelic given above and which were taken from Apter (2005, pp. 6-7). The second domain is Conformist and 
Negativistic, which relates to rules, where the conformist is this who follows the roles, while the negativistic is the one who does not abide by the roles and does things differently. Apter (2005, p. 10) says that "the conformist style is essentially adaptive ... the style of the negativistic state is rebellious, challenging and confrontational". In addition, "the conformist state represents the value of duty, while the negativistic state represents the value of freedom".

The third domain is Mastery and Sympathy, which relates to the experience of the way of interaction with others, including persons, things and situations. In this domain we have two ways of experiencing interaction. The first mastery that sees interaction in terms of control, so gaining or losing from an interaction is seen in terms of becoming competent and able, or incompetent and unable respectively. The sympathy state can be seen "in terms of caring: of wanting to develop close and nurturing relationships". The fourth domain is Autic and Alloic, which is related to orientations - on whose behalf we are doing what we are doing. In the autic state, the desire is to benefit personally from what we do. While in the alloic state, the desire is to benefit others. In the four previous domains, one state from each domain is active at a time, where switches occur from one state to the other within each pair depending on the conditions of the experience. The opposite states in a pair cannot function simultaneously as they represent opposite ways of seeing the world.

Three causes could activate the switches/reversals between one state in a domain into the second state of the same domain. The first cause include situations, circumstances, or events. The second cause of reversals is frustration. The third cause of reversals is satiation that can result when a particular state has been active for a certain time, with nothing happening meanwhile to encourage a reversal through situation change or frustration.

Apter (2005) relates the four motivational domains and their states to emotional states. Emotional states could be related to couples of motivational states (Apter, 2005 , p. 12). In the alloic and mastery states, enjoyment can result from the skill of someone one is teaching. In the autic version of the sympathy state, one wants to feel loving, while in the alloic version of the sympathy state, one wants to be loved by others. When the activity has priority and the goal is subsidiary, the aim is to enjoy the activity itself, where in this case, the goal serves as enhancing the pleasure (Apter, 2005, p. 7). On the other hand, when the goal has the priority, as in the case of winning, enjoyment happens when you get the goal (Apter, 2005, p. 7). Negative emotions could be associated with the activity and goal states in the same way. Concerning the autic and alloic states, as well as the mastery and empathy states, Apter (2005, p. 12) says that what is pleasant in the autic (self-oriented) state becomes unpleasant in the alloic (other oriented) state, and vice- versa, where the previous claim applies to the mastery and sympathy states. One example on emotions in the alloic and mastery states is the enjoyment of the increasing skill of someone one is teaching.

In reversal theory, not only motivational states are related to emotions, but also combinations of motivational states. Apter (2005, p. 12) says that one wants to feel loved in the autic- sympathy combination, while one prefers to feel loving in the alloic-sympathy combination. Moreover, in the paratelic-conformist states combine, immediate pleasure will be sought from doing something according to the rules. On the other hand, in the paratelic-negativistic states combine, the pleasure may come from doing something one should not do.

\section{Research Rationale and Goals}

Motivation to learn mathematics could have positive effects on students' learning (Michaelides et al., 2019). Thus, increasing this motivation is a requested act by the teacher. One way to do so is by providing students with activities whose features are expected to raise students' motivation to engage in them. One such activity is the modelling activity that is expected to motivate students to engage in the mathematical processes as it encourages students' freedom to take decisions. The modelling activity in the present research is related to birds mentioned in history books.

Generally, research on students' motivation to learn mathematics has been done quantitively (e.g., Higgins, Huscroft-D’Angelo, \& Crawford, 2019). Little research has studied qualitatively students' motivation in learning mathematics. Hannula (2006) developed a theoretical foundation of motivation as a structure of needs and goals. Doing that he took advantage of needs of autonomy, competence and social belonging. Similarly, Wæge (2010) proposed a theoretical framework for analyzing students' motivation in learning mathematics in terms of psychological needs for competence, autonomy and relatedness. Here, he depended on on self-determination theory. Another suggested framework for studying qualitatively students' motivation in learning mathematics is that of Lewis (2015) who depended on the reversal theory to suggest studying motivation in the mathematics classroom using the reversal theory. Studying students' motivation in the mathematics classroom is still in its infancy. The present research intends to study Grade 9 students' motivation when they carry out a modelling activity using the Internet and GeoGebra. The present research uses the reversal theory of motivation developed by Apter (2005) to investigate these students' motivation when engaging in the modelling activity. 


\section{Research Questions}

1. What motivational styles are present in the modelling activity processes?

2. What motivational patterns are present in the modelling activity processes?

\section{METHODOLOGY}

\section{Research Contexts and Participants}

The present research was conducted in a middle school and specifically with Grade 9 students. Three groups of 4-5 students participated in the research, and they carried out a modelling activity called the Roc bird. The groups used the internet and GeoGebra to carry out this activity and they were engaged with a subset of the modelling processes described in Daher and Shahbari (2015) as processes in which students utilize technology in their modelling activity. In the present research, we focus on the technology-based modelling processes of one such group. We focus on one group as we want to show the motivational styles and patterns followed by sequence of modelling processes followed by Grade 9 students to solve the Roc modelling activity. Similar motivational styles and patterns were followed by the other groups. The group reported in the present research consists of four students: Samira, Farah, Huda and Amira. Samira was a high-achieving student in mathematics, while the other three students were middle-achieving students in mathematics.

The Roc activity:

Historians and travellers described the Roc bird as a huge bird whose place is Madagascar. Writers differed in their description of the bird, but they all agreed that it is a huge one. Search the internet for information about this bird and use GeoGebra in order to build a model of the body of the bird.

\section{Data Collecting and Analysis Tools}

The three groups were requested to video record their work in the group while carrying out the modelling activity. The videos were collected from them as well as the texts of their solutions.

To analyze the data, we used inductive and deductive content analysis. Inductive qualitative content analysis is a process designed to put collected data into categories or themes on the basis of valid inference by using inductive reasoning. Deductive reasoning is used to generate concepts and categories or themes based on a theoretical framework (Patton, 2002). Using deductive reasoning, we looked for themes related to motivational processes such as in Apter (1995). In addition, for technology-based modelling processes, we looked at processes as described in Daher and Shahbari (2015) that based on Blum and Lieb (2005) modelling cycle, where these processes included taking decisions regarding the characteristics of the technological environment to be built with the specific technological tool, discussing performing mathematical actions in the technological environment, taking management decisions that fit the technological environment, building the model in the technological environment, and validating the technological mathematical model with real examples.

Using the inductive reasoning, we tried to find out if additional themes related to motivational processes, and those not given in the literature were present in the data. In the deductive reasoning, we followed our previous utilization of these methods (e.g., Daher \& Awawdeh Shahbari, 2020). To elaborate more, the inductive reasoning consisted of looking for sentences that symbolize a motivation process related to one of the motivati

onal types in Apter (2005). Table 1 includes terms indicating each theme/category related to the motivation variable, in addition to an example on each of these themes/categories.

Table 1. Examples of themes related to the motivation variable

\begin{tabular}{|c|c|c|}
\hline Theme/category & Terms & Examples \\
\hline Goal & $\begin{array}{l}\text { 'Our goal is ...', 'The requirement of the task is ...', } \\
\text { 'To arrive at our target, we ...' }\end{array}$ & $\begin{array}{l}\text { 'Everything that we do should be to achieve our } \\
\text { goal that is a model of the Roc bird' }\end{array}$ \\
\hline Activity & 'do', 'perform', 'carry out' & "We need to search the internet for ... \\
\hline Conforming & $\begin{array}{l}\text { 'I agree', 'let us do what you ...', 'We need to follow } \\
\text { the task givens' }\end{array}$ & “For me, your suggestion seems perfect. \\
\hline Rebellious & $\begin{array}{l}\text { 'I do not agree', 'It is not appropriate', 'it is not } \\
\text { applicable' }\end{array}$ & $\begin{array}{l}\text { "I think there is a problem with your } \\
\text { suggestion" }\end{array}$ \\
\hline Mastery & $\begin{array}{l}\text { 'I will perform ....', 'It is important for me to ...' ', 'I } \\
\text { need to master ....' }\end{array}$ & $\begin{array}{l}\text { "I will search the internet for measurements of } \\
\text { the parts of huge birds" }\end{array}$ \\
\hline Sympathy & $\begin{array}{l}\text { 'Is it difficult for you to ...', 'Do you need ...', } \\
\text { 'Would you please',' }\end{array}$ & $\begin{array}{l}\text { "Do you understand why we are satisfied with } \\
\text { the measurements of the small bird?" }\end{array}$ \\
\hline Self-oriented & 'It is important for me to ...', 'I can ....', 'I need to ...' & $\begin{array}{l}\text { 'It it important for me to search the internet first } \\
\text { and then discuss the matter' }\end{array}$ \\
\hline Other-oriented & $\begin{array}{l}\text { 'It is important for the group to ...', 'We can ....', } \\
\text { 'The group needs to ...' }\end{array}$ & $\begin{array}{l}\text { 'It is important for the group to take cases of } \\
\text { huge birds' }\end{array}$ \\
\hline
\end{tabular}


Table 2. Examples of motivational patterns

\begin{tabular}{|c|c|c|}
\hline Motivational style & Emotion & Example \\
\hline Goal & Confidence & $\begin{array}{l}\text { We need to draw a line that is more similar to the bird's wing [She seemed } \\
\text { confidence of herself] }\end{array}$ \\
\hline Activity & Enjoyment & $\begin{array}{l}\text { [she attempted to draw a circular arc that is similar to the wing. Each time the other } \\
\text { members suggested to improve the line. The three girls seemed enjoying the process] }\end{array}$ \\
\hline Conforming & Hesitation & $\begin{array}{l}\text { I will search the internet for measurements of the parts of huge birds. I wonder } \\
\text { whether we could find them. }\end{array}$ \\
\hline Rebellious & frustration & $\begin{array}{l}\text { [She drew a line segment between the ends of outer length of one wing] No, I do not } \\
\text { think this is appropriate [She seemed frustrated]. We need to look for another way. }\end{array}$ \\
\hline Mastery & Satisfaction & $\begin{array}{l}\text { I found on the internet that common ratios include } 1: 10,1: 100,2: 1 \text {, and } 4: 1 \text { [She } \\
\text { seemed satisfied of herself]. }\end{array}$ \\
\hline Sympathy & Enthusiasm & $\begin{array}{l}\text { It seems that we need to start by considering the wings and the distance between } \\
\text { them [She seemed enthusiastic to offer the group such suggestion]. }\end{array}$ \\
\hline
\end{tabular}

Table 3. Examples of themes related to the modelling phases

\begin{tabular}{lll}
\hline Theme/category & Terms & Examples \\
\hline Taking decisions regarding the & 'Which command to use in GeoGebra', 'I & "how to ensure that the results on \\
characteristics of the technological & will put brackets to ensure that I get ...', & the internet give measurements for \\
environment to be built with the & 'We need to use the command ....' & huge birds?
\end{tabular}

specific technological tool

Discussing performing mathematical 'How to measure the ... in GeoGebra?' , 'I [Pointing at the bird in the image in actions in the technological environment will try to find on the internet the common GeoGebra] Can we measure this scales of ...', 'Can we draw an appropriate bird's back? line in GeoGebra'

Taking management decisions that fit 'Who would work with GeoGebra to ...', "Would we use GeoGebra or the the technological environment 'let us first ... in GeoGebra', 'It is better to internet first?" use first the ....'

Building the model in the technological 'Ratio of the parts of the bird in 'We need to symbolize the ratios of GeoGebra', 'How to symbolise the scale?', the bird's parts that we found in 'Symbolizing the ratios of the parts' GeoGebra to

Validating the mathematical model with real examples based on the internet 'I cannot see the measurements of the Roc', "We can assume that the scale is 'One example of the model is ...', 'Let us 1000 as we are talking about a huge suppose that the scale is ...' Roc"

Table 2 describes examples of themes related to motivation and emotion patterns. The patterns were chosen arbitrarily.

Table 3 describes examples of themes related to the modelling phases.

\section{FINDINGS AND DISCUSSION}

The present research intended to verify the motivational styles and patterns in mathematical modelling with technology. Here, we analyze the learning of one of the three groups that participated in the research, where similar motivational styles and patterns emerged in the learning of the other two groups. Doing that, we focus on the four technologybased modelling phases of the participating groups and which were described by Daher and Shahbari (2015). We detail each process with exemplification from students' modelling work. In reporting and analyzing each phase, we focus first on the motivational styles and then on the motivational patterns.

\section{Taking Technological Decisions}

The process of taking technological discussions included students' discussion of the appropriate way to measure the wing of the Roc bird in GeoGebra and take decisions regarding how to do so. At the beginning, they searched on the internet for pictures of birds that were similar to the Roc bird. Finding one, they tried to find their way in GeoGebra to use it for measuring the wing of the huge bird. Transcript 1 describes students' search, in the internet, for pictures of huge birds, and their work with GeoGebra to find the length of the bird's wing.

99 Group [The members of the group searched the internet using their phones for pictures of huge birds]

100 Samira [In confidence] Do not forget the givens in the Roc story. When the bird is small the distance between his wings is 25 centimeters, but when it is big the distance is 10 meters.

101 Farah [In hesitation] Could that be true? 
102 Huda It seems that we need to start by considering the wings and the distance between them [She seemed enthusiastic to offer the group such suggestion].

103 Samira [In confidence] Do not forget that we are looking at pictures, so we need to consider distance in the scale setting.

104 Teacher Your discussion seems interesting. 105 Samira I found one [She looked satisfied].

106 Huda I found one too. I will insert the picture in GeoGebra and find its measurements [She inserted the picture in GeoGebra using the group's laptop]. I succeeded [She seemed proud to do this act]

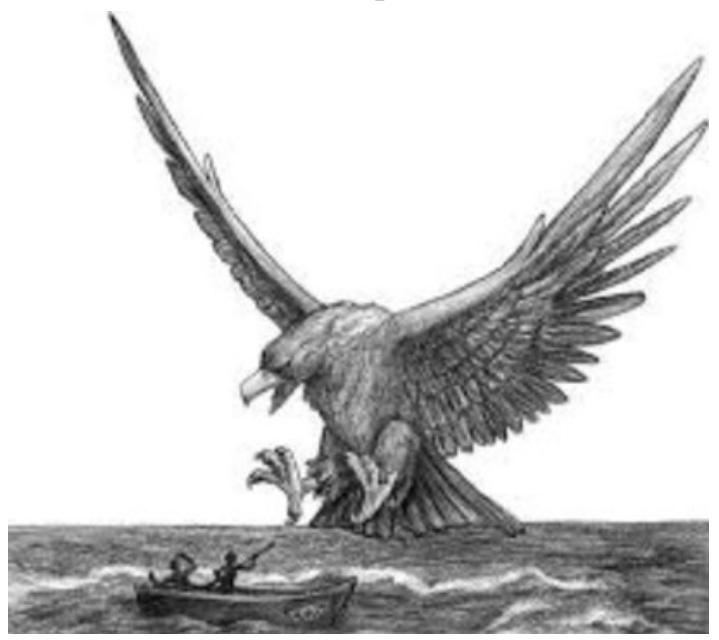

107 Farah [In confidence] We need to find the length of its wing. I will do that. Which length of the wing to take? [She looked at the other members for help]

108 Amira Maybe the outer one.

109 Farah [She drew a line segment between the ends of outer length of one wing] No, I do not think this is appropriate [She seemed frustrated]. We need to look for another way. [She Looked for help at Huda and Samira]

108 Huda How do we do that in GeoGebra. They are not straight lines [She addressed the teacher] How can we find the length of the wings in GeoGebra?

109 Teacher Look for the Geometric objects that you can draw in GeoGebra. You can do guess and test to find these objects.

110 Group [The group discussed which objects in GeoGebra could help in drawing a line similar to the bird's wing].

111 Samira We can use the Circles part. What about the Circular Arc.

112 Farah But where is the centre of the arc?
113 Samira We can guess that [She seemed confident of herself].

114 Farah O.K. [she attempted to draw a circular arc that is similar to the wing. Each time the other members suggested to improve the line. The three girls seemed enjoying the process].

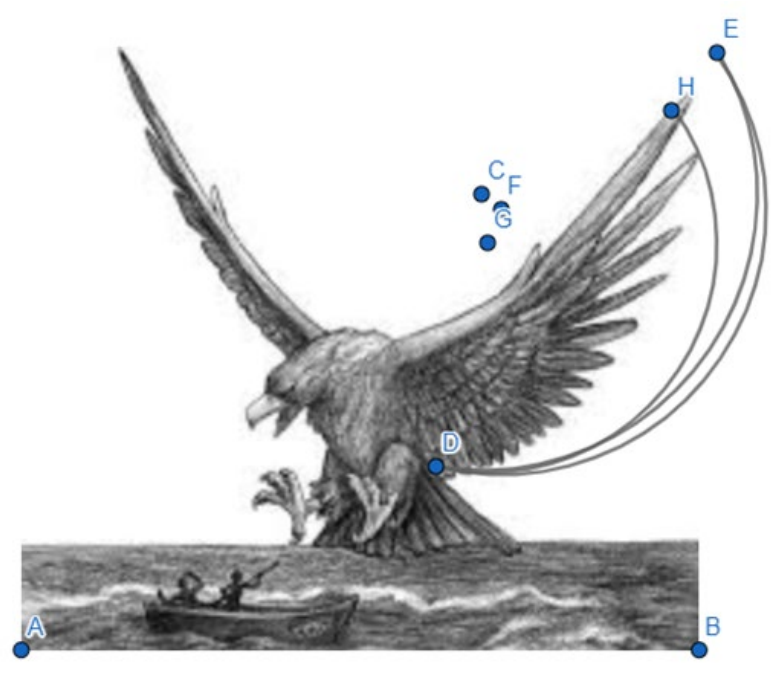

115 Amira [In frustration] It is a bit similar though not enough.

116 Samira Why do not we try the Circumcircular arc?

117 Farah O.K. [she attempted patiently to draw a circumcircular arc that is similar to the wing].

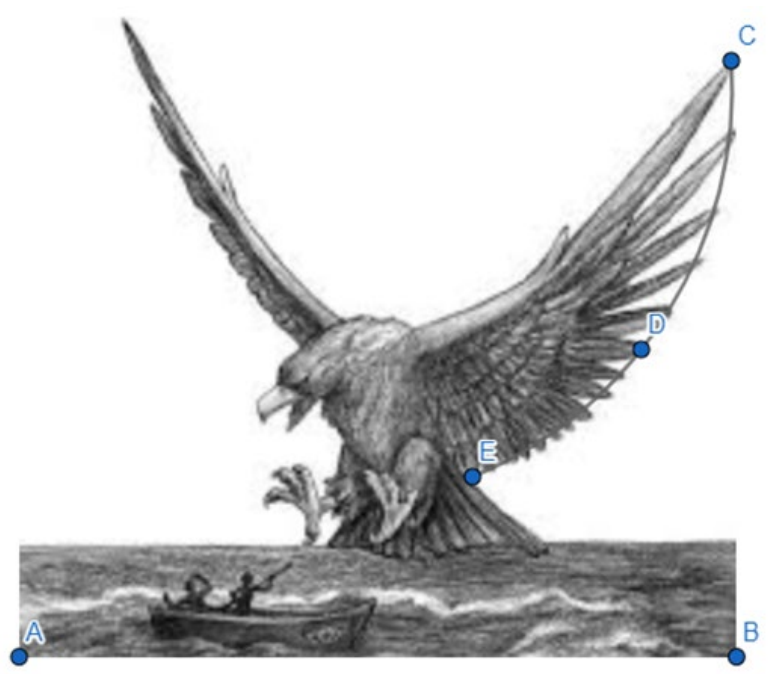

118 Amira [with satisfaction] Oh, it is similar to the wing more than the previous ones.

Transcript 1: Searching the internet for appropriate birds and measuring them in GeoGebra

\section{Motivational styles during taking technological decisions}

During their searching the internet for pictures of huge birds, the group members showed awareness of 
taking care of the features of the bird when searching for a representative of it in a picture form. Samira, from the beginning, behaved according to a sympathy motivational style, taking care of the group's learning, and directing the group regarding the givens of the modelling problem [R100]. Doing that, Samira showed confidence of her actions. Huda, following the interaction between Samira and Farah, tried to direct the group towards the beginning of their investigation of the modelling problem in the technological environment [R102]. Samira did this suggestion in a sympathy style accompanied with confidence in the suggestion. This sympathy style reversed into mastery style as Samira took the lead in searching the internet for a huge bird [R105]. This mastery style was continued by Huda and Farah [R106-R107] as they went to work personally with GeoGebra. Huda took the lead in inserting the picture in GeoGebra, while Farah took the lead in trying to draw in GeoGebra a line similar to the wing of the bird. These mastery motivation styles were accompanied by positive emotions, as satisfaction and pride [R105-106] and negative ones, as frustration [R107]. These emotions were influenced by the success or failure of the processes (Pekrun, 2006), here related to the mastery motivation style.

Along the carrying out of the modelling process, all the members of the group had a conforming motivational style, as they abided by the rules of the activity, for example using GeoGebra to find the length of the bird wing. This conforming was reversed to a rebellious motivation style when Samira led the group to the use of a different GeoGebra object to draw a line more similar to the wing [R116]. This reversal was due to the frustration (Apter, 2005), here from the lines drawn by another object of GeoGebra [R115], as these lines were not sufficiently similar to the bird's wing [R114]. In the present research, conforming and rebellious motivation styles were associated with taking technological decisions, specifically the type of GeoGebra object that could be most similar to the line that depicts the huge bird's wing. Here, frustration, when regulated, resulted in rebellious motivation processes that led into cognitive processes, enabling the achievement of the learning goal (Baker et al., 2008).

The group's experience of the motivational goal and activity styles consisted of the combination of the two styles along the whole transcription. Samira and Huda attended to the sub-goals of solving the problem, when they stated what the group needs to consider at the beginning for achieving the final goal, which is the building of the mathematical technological model [R100, R102-R103]. This goal style continued all along the transcription, but it was also accompanied by the activity style as the sub-goals implied the activity processes that need to be followed by the group in order to succeed in solving the modelling problem. Specifically, the group had an activity motivation style during their work with
GeoGebra, for example when they had a sequence of steps for drawing a line similar to the bird's wing [R114]. This activity style was accompanied by positive and negative emotions according to the success or unsuccess of the technological actions.

\section{Motivational patterns during taking technological decisions}

The motivational patterns that the group followed varied. The first modelling phase involved taking technological decisions. During this phase, the group members generally experienced sympathy-conformist motivational styles, which were accompanied by positive emotions, especially confidence and sometimes satisfaction. Svebak (1988) says that pleasant emotions could be related to feeling strong. Confidence and satisfaction could be considered as such pleasant emotion. The motivation style sometimes turned into sympathy-rebellious styles. These motivational patterns show that the rebellious style, though started by one group member, can serve the whole group's work as in the phase discussed here. This argument is supported by Svedberg's (1997) claim that the individual's self-image is socially determined by that of the collective. Here, the collective self-image included negative emotions element, which resulted in a rebellious motivation style that benefited the activity of the group. In the first technological modelling phase, the group members also experienced the mastery-conforming motivational pattern as they utilized the technological tools, whether the internet or GeoGebra. Here, this pattern indicates that confirming to technology serves the individual member of the group to compete with the other members of the group in carrying out the modelling processes involved in the specific modelling activity. The mastery-conforming styles were accompanied by positive emotions as satisfaction and pride.

\section{Discussing Mathematical Actions in the Technological Environment}

After finding pictures for appropriate birds and succeeding in measuring the wing of such a bird, the group turned to discuss scales of drawing in order to decide upon the actual lengths of the parts of the bird.

120 Samira [With concern] We need to decide upon the scale in order to arrive at the real measurement.

121 Huda [In confidence] We could search the internet for scales of drawings.

122 Amira [said with confidence] We can find the scale by dividing the length of the wing of specific bird in a drawing to that in reality.

123 Huda I found on the internet that common ratios include 1:10, 1:100, 2:1, and 4:1 [She seemed satisfied of herself]. 
124 Samira [In confidence] I suppose the ratio is even more than that because we are talking about a huge bird like the Roc.

125 Amira [In hesitation] Maybe 1:1000.

126 Teacher What do we do when we do not know the exact value?

127 Huda What?

128 Teacher Think about it.

Transcript 2: Discussing scales of drawing

\section{Motivational styles in discussing mathematical actions in the technological environment}

In discussing mathematical actions in the technological environment [R120-R128], the group members were motivated mainly by a sympathy motivational style, probably because discussion is an action in which the whole group is engaged with (Williams, 2011). In this mathematical situation, the sympathy motivational style was accompanied with positive emotions as confidence and concern. Huda was engaged in a mastery motivational action, reporting her performance of finding common ratios related to drawing creatures [R123]. Samira's engagement was also according to the same sympathy motivational style, when she suggested a different scale from those found on the internet [R124]. Here too, the motivational style was accompanied by positive emotions as confidence and satisfaction.

The group members were motivated following the conforming style as they conformed to the task conditions that included using technological tools to build a model of the Roc bird. This conforming indicates the advantages they utilized as they used the technological tools (Daher, 2014). They confirmed to the information found on the internet, but did not confine within it, regarding the drawing scale, as they took into consideration the dimensions of the huge bird [R124]. Doing that, they attended first to the sub-goal, which is arriving at the real measurement of the huge bird [R120]. To do so, they were engaged in mathematical processes, as discussing the mathematical actions, and technological processes, as searching the internet for drawing scales [R121-R128].

\section{Motivational patterns in discussing mathematical actions in the technological environment}

In the second modelling phase, the group members followed both sympathy-conforming and masteryconforming styles in addition to mastery-rebellious style, where they used the last style when they did not get the appropriate drawing scales by looking for scales on the internet. Here, the reversal was not a result of frustration, but to fit the scale to the context. Apter (2005) describes this reversal as resulting from satiation that can happen when a particular state has been active for a certain time, with nothing happening meanwhile to encourage a reversal through situation change (Apter, 2001). Here, the state that has been active; as prevailing on the Internet, is the 'regular birds', where it changed into 'huge birds'.

\section{Building the Model in the Technological Environment}

Deciding upon appropriate scales of drawing, the group began building the mathematical model in the technological environment. This included work with GeoGebra and taking mathematical decisions, especially using parameters.

129 Samira [In confidence] I agree with Amira. Let us measure all the body parts of the bird in GeoGebra and multiply by a number that is a multiple of 100 .

130 Farah I will do the measurements [She measured the body parts of the bird using the measurement option in GeoGebra. She seemed enjoying her doing].

131 Samira I prefer to build a table that shows the parts of the Roc, the length of the parts in GeoGebra and their real lengths [She seemed satisfied of her suggestion].

132 Huda I will build the table [She started to build a three-column table, where in the first column she puts the parts: outer wing, inner wing, feather, and flank].

133 Samira [In confidence] We need to take care of other parts of birds.

134 Amira Which parts?

135 Farah I will look for the parts on the internet [She opens the search engine page and looks for the term "parts of the bird"]. We can add: leg, foot, back, head, and beak [She seemed satisfied of her doing].

136 Farah Can we measure this bird's back. It is not really obvious how to do it ... maybe the leg also [She seemed in need of help].

137 Samira We can find the ratios of the parts in a bird and apply it to the bird whose picture we put in GeoGebra.

138 Huda [With confidence] I can look for these ratios [She starts to search the internet for the ratios] I cannot find such ratios.

139 Samira We find the lengths of the parts and then the ratios between them.

140 Huda [Continues to search the internet; this time for the length of the parts] I found the length of the wing, not all the parts. I will keep searching [She seemed nervous]. 
141 Farah [With concern] I will search the internet too.

142 Huda I found something interesting. The lengths are different for male and female birds. Of course, they are also different for adults and young. [She seemed satisfied with her finding]

143 Farah Yeh, interesting.

144 Huda [Showing anxiety] The measurements I found are not for huge birds, but for small ones. I cannot find measurements for huge or big birds. What to do?

145 Farah [In hesitation] I suggest considering the ratios for small birds.

146 Huda [Showing helplessness] How can we do that?

147 Samira I suggest considering the ratio as a parameter, together with the drawing scale. First we need to multiply the measurements in GeoGebra by $r$ that symbolizes the drawing scale. These multiplications give us the lengths of some parts of the Roc. To find the other parts, we use the ratios that we assumed to be parameters [She seemed proud of her suggestion].

148 Group [the group members engaged in carrying out the mathematical processes described by Samira, and thus built a model for the Roc bird. Doing that, they appeared satisfied of their mathematical doing].

Transcript 3: Building a mathematical model with the help of technology

\section{Motivational styles in building the model in the technological environment}

In building the technological mathematical model, the group members were motivated mainly by a mastery motivational style as each of them contributed personally to the development of the model [R129-R132]. This mastery motivational style was accompanied with positive emotions as confidence, satisfaction and enjoyment. This is in line with Benita, Roth and Deci (2014) who found that stronger relations of mastery goals with interest and occur when students perceived their level of choice as high rather than low. Here, the group's work encouraged the perception of choice. The mastery style reversed into a sympathy one when Samira gave directions to the group's building of the model [R137, R139, part of R147]. Here, the sympathy and the mastery styles intermingled as the group performed collective and individual actions to act successfully in the mathematics situation. The positive and negative emotions accompanied both the sympathy and the mastery motivational styles.

The group members followed the conforming style as they conformed to the task conditions. They reversed into the rebellious motivational style when they could not find measurements for a huge bird, so they agreed to work with the measurements of a small bird [R145]. Here, the rebellious style followed students' negative emotions accompanied with their unsuccessful technological actions. This is in line with studies that reported the positive impact of negative emotions on students' learning (D'Mello et al., 2014). Here this positive impact happened through a rebellious action. The reversal motivational action also happened when Samira suggested using parameters for the ratio instead of a number [First sentence of R147]. This also followed negative emotions expressed by Huda [R146]. In addition, here too, what motivated the group is the goal that they wanted to achieve, i.e., building a technological mathematical model for the Roc bird [R147-R148]. This goal-motivation style encouraged activity motivation style, as the students engaged to perform activities that made them arrive at their goal [R129-R148]. The activity was accompanied with positive and negative emotions according to fulfilling or not its goal.

\section{Motivational patterns in building the model in the technological environment}

Performing the third modelling phase, the group followed mainly the mastery-conforming motivational pattern, but also other patterns as the sympathyconforming and mastery-rebellious. These patterns show the importance of patterns that include mastery to the building-of-products process, here building of the technological mathematical model. In addition, the rebellious style came here in a pattern that included the mastery type. This pairing could indicate that a person who takes responsibility on her or his actions, especially in a rebellious motivational style, would do so to contribute to the group's achievement of goals, here the technological mathematical model. The patterns that included the mastery style, at this modelling phase, were accompanied with positive emotions, as confidence, satisfaction and pride, when succeeding to advance in the building of the model. The emotion of satisfaction was especially prominent in this phase, which could be attributed to the phase being the phase of the goal of the modelling activity. The relatively low prominence of the satisfaction emotion is that this is a low arousal emotion, and thus is unlikely to be experienced intensely (Lewis, 2015). This is not the case in this phase that involved direct addressing of the goal of the modelling activity. 


\section{Validating the Mathematical Model with Real World Examples Taken from the Internet}

After building the mathematical model, the group validated with examples of real birds. It was difficult for them to find measures of big birds' parts, so they worked with those of small ones.

152 Huda [Showing anxiety] I do not understand. Did we get the lengths of the body parts of the roc?

153 Samira We did that in general. Now we can compute the lengths of the body parts of some specific huge birds that resemble Rocs. We can now consider one such Roc and find the lengths of its parts.

154 Huda [In hesitation] I think I am beginning to understand.

155 Samira [In confidence] We have two general factors that we can give specific values and thus get the measurement of a specific Roc. The first factor is the scale and the second is the ratios between the parts of the Roc.

156 Amira Right, the model includes these two factors.

157 Huda [With satisfaction] I already found on the internet the measurements of the body parts of a small bird. Could we take the ratios depending on these measurements?

158 Samira What are these measurements Huda?

159 Huda Foot span 45.4-51.5 mm with mean score $49 \mathrm{~mm}$, middle toe $28.2-32.3 \mathrm{~mm}$ with mean score $30.2 \mathrm{~mm}$, hand-wing 191-221 mm with mean score 200.8 , wing 248 $276 \mathrm{~mm}$ with mean score $265.8 \mathrm{~mm}$, tail 115-139 with mean score $122.7 \mathrm{~mm}$, and body $257-278 \mathrm{~mm}$ with mean score 267.7 $\mathrm{mm}$.

160 Samira [In confidence] We can assume that the scale is 1000 as we are talking about a huge Roc.

Transcript 4: Validating the mathematical model with real world examples taken from the internet

\section{Motivational styles in validating the mathematical model with real world examples taken from the internet}

In validating the mathematical model with real world examples taken from the internet, the group members used both sympathy and mastery motivational styles. They were engaged with the mastery style to express present states related only to them as their understanding or absence of understanding [R152, R154]. In this case, this mastery motivation was accompanied with non-positive emotions according to the present state of the group's member, in this case Huda. The group regulated this non-positive emotions through the sympathy motivation expressed by Samira [R153, R155]. It could be said that the group "is already engaged in the transaction and so incorporates strategies to produce a situation-appropriate response" (Schutz et al., 2006, p. 348). In addition, the group's members were engaged with the mastery style to express actions that they did in the past [R157]. In this case, this motivation style was accompanied with positive emotion as the past action expressed positive performance of the member. The members were engaged with the sympathy motivational style to express present actions needed to be performed by the group [R153], to talk about the present state of the mathematical model [R155], or to talk about mathematical assumptions [R160]. In the later two cases, positive emotions accompanied the motivation style.

The group members were motivated following the conforming style as they conformed to their previous mathematical doing by depending on the technological mathematical model that they built previously (Daher \& Shahbari, 2015). Here, the group's members followed the conforming style to base their computations needed to find one example of the Roc bird. As in their previous modelling processes, the activity processes motivated the group members to arrive at their goal, here a specific example of the Roc bird.

\section{Motivational patterns in validating the mathematical model with real world examples taken from the internet}

Performing modelling processes in the fourth modelling phase, the group utilized the sympathyconforming and the mastery-conforming motivational patterns, but not patterns that included the rebellious motivational type. This absence of the rebellious type in the motivational patterns at this modelling phase could be related to the validation process in which the students were engaged and that consisted of searching the internet for measurements of the bird's parts and using these measurements to arrive at those of the huge bird by applying the previously constructed model.

\section{CONCLUSIONS}

Working in a group helped the group's members experience the sympathy motivational style, where the whole group worked towards achieving a common goal. The group's members experienced the mastery motivational style while working with the technology tools, whether the internet or GeoGebra. The technological tools facilitated the group's work through the individual work of each member. Thus, though we can point at some actions of the group members as related to mastery motivational style, indicating 
competence among the group's members, these actions were part of the group's doing towards the achievement of a collective goal (Barak, Maymon, \& Harel, 1999), which indicates the experiencing of sympathy motivation. The previous argument shows that the sympathy and mastery motivational styles were complimentary in the modelling processes of the group (Galbraith \& Holton, 2018).

The group's members generally experienced the conforming motivational style in their successful utilization of the internet and GeoGebra technologies to arrive at the mathematical model of the Roc bird. They reversed into the rebellious motivational style when their technological or mathematical actions did not yield the expected outcome, which led to their frustration from their technological actions. This happened when technological action in GeoGebra or the internet did not yield the expected mathematical outcome. Apter (2005) describes reversal as activated by frustration. Here, the frustration was due to the mathematical outcome resulting from the technological action. Rowe and Fitness (2018) say that "While negative emotions were frequently viewed as detrimental to motivation, performance and learning, they were also construed under some circumstances as beneficial". Here, the students' frustration, in the presence of different options of the technological tools, motivated the group to search for different options that would make the mathematical outcomes more accurate.

Carrying out the modelling activity using the internet and GeoGebra, the group members were engaged with a goal-based motivational style that was accompanied by an activity-based motivational style. This engagement with a goal-based motivational style could be expected in model eliciting activities (Biccard \& Wessels, 2011). As indicated above, positive emotions accompanied successful students' activity, while negative ones accompanied less successful engagement in activity-based motivational styles.

The group's members generally experienced sympathy-conformist motivational pattern, which were accompanied by positive emotions, especially confidence and satisfaction. The previous patterns were followed to arrive at the sub-goals associated with building a technological mathematical model of the Roc bird. They also experienced the mastery-conforming motivational pattern as they utilized the technological tools, whether the internet or GeoGebra. The previous patterns indicate that technology-based mathematical modelling encourages different motivational patterns. Its grounding in modelling encourages patterns in which the sympathy style is part, where this is due to the modelling activity being carried out in groups to facilitate this carrying out (Daher \& Shahbari, 2015). In addition, its grounding in technology encourages the mastery-conformist pattern to be followed. This encouraging is due to that technological tools facilitate problem solving (Daher, 2009). Moreover, they could be manipulated by the individual's actions (Daher \& Baya'a, 2012).

Author contributions: All authors have sufficiently contributed to the study, and agreed with the results and conclusions.

Funding: No funding source is reported for this study.

Declaration of interest: No conflict of interest is declared by authors.

\section{REFERENCES}

Apter, M. J. (2001). An introduction to reversal theory. In M. J. Apter (Ed.), Motivational styles in everyday life: A guide to reversal theory (pp. 3-35). American Psychological Association. https://doi.org/ 10.1037/10427-001

Arseven, A. (2015). Mathematical modelling approach in mathematics education. Universal Journal of Educational Research, 3(12), 973-980. https: / / doi.org/10.13189/ujer.2015.031204

Arzarello, F., Ferrara, F., \& Robutti, O. (2012). Mathematical modelling with technology: the role of dynamic representations. Teaching Mathematics and Its Applications: International Journal of the IMA, 31(1), 20-30. https://doi.org/10.1093/teamat/ hrr027

Baker, R., Walonoski, J., Heffernan, N., Roll, I., Corbett, A., \& Koedinger, K., (2008). Why students engage in "Gaming the system" behavior in interactive learning environments. Journal of Interactive Learning Research, 19(2), 185-224.

Bal-Taştan, S., Davoudi, S. M. M., Masalimova, A. R., Bersanov, A. S., Kurbanov, R. A., Boiarchuk, A. V., \& Pavlushin, A. A. (2018). The impacts of teacher's efficacy and motivation on student's academic achievement in science education among secondary and high school students. EURASIA Journal of Mathematics, Science and Technology Education, 14(6), 2353-2366. https://doi.org/ 10.29333 /ejmste/ 89579

Barak, M., Maymon, T., \& Harel, G. (1999). Teamwork in modern organizations: implications for technology education. International Journal of Technology and Design Education, 9(1), 85-101. https://doi.org/ 10.1023/ A:1008849803984

Bawaneh, A. K., \& Moumene, A. B. H. (2020). Flipping the classroom for optimizing undergraduate students' motivation and understanding of medical physics concepts. EURASIA Journal of Mathematics, Science and Technology Education, 16(11), em1899. https:/ / doi.org/10.29333/ ejmste/8561

Benita, M., Roth, G., \& Deci, E. L. (2014). When are mastery goals more adaptive? It depends on experiences of autonomy support and autonomy. Journal of Educational Psychology, 106(1), 258. https://doi.org/10.1037/a0034007 
Biccard, P., \& Wessels, D. C. (2011). Documenting the development of modelling competencies of grade 7 mathematics students. In G. Kaiser, W. Blum, R. Borromeo Ferri, \& G. Stillman, (Eds.), Trends in teaching and learning of mathematical modelling (pp. 375-383). Springer Nature. https:/ / doi.org/10.1007 /978-94-007-0910-2_37

Blum, W. (1995). Applications and modeling in mathematics teaching and mathematics education - some important aspects of practice and of research. In C. Sloyer et al (Eds.), Advances and perspectives in the teaching of Mathematical modeling and Applications (pp. 1- 20). Water Street Mathematics.

Blum, W., \& Leiß, D. (2005). "Filling Up"-the problem of independence-preserving teacher interventions in lessons with demanding modeling tasks. In M. Bosch (Ed.), Proceedings of the Fourth Congress of the European Society for Research in Mathematics Education (CERME 4) (pp. 1623-1633). Fundemi Iqs, Universitat Ramon Llull.

Bomia, L., Beluzo, L., Demeester, D., Elander, K., Johnson, M., \& Sheldon, B. (1997). The impact of teaching strategies on intrinsic motivation. ERIC Clearinghouse on Elementary and Early Childhood Education. (ERIC Document Reproduction Service No. ED 418 925).

Bora, A., \& Ahmed, S. (2019). Mathematical modeling: An important tool for mathematics teaching. International Journal of Research and Analytical Reviews (IJRAR), 6(2), 252-256.

D'Mello, S., Lehman, B., Pekrun, R., \& Graesser, A. (2014). Confusion can be beneficial for learning. Learning and Instruction, 29, 153-170. https://doi.org/10.1016/j.learninstruc.2012.05.003

Daher, W. (2009). Preservice teachers' perceptions of applets for solving mathematical problems: Need, difficulties and functions. Journal of Educational Technology \& Society, 12(4), 383-395.

Daher, W. (2014). Students' adoption of social networks as environments for learning and teaching: The case of the Facebook. International Journal of Emerging Technologies in Learning, 9(4), 16-24. https:// doi.org/10.3991/ijet.v9i8.3722

Daher, W. (2015). Discursive positionings and emotions in modelling activities. International Journal of Mathematical Education in Science and Technology, 46(8), 1149-1164. https://doi.org/10.1080/ 0020739X.2015.1031836

Daher, W. M., \& Shahbari, J. A. (2015). Pre-service teachers' modelling processes through engagement with model eliciting activities with a technological tool. International Journal of Science and Mathematics Education, 13(1), 25-46. https://doi.org/10.1007/ s10763-013-9464-2
Daher, W., \& Awawdeh Shahbari, J. (2020). Secondary students' identities in the virtual classroom. Sustainability, 12(11), 4407. https:/ / doi.org/10.3390 /su12114407

Daher, W., \& Baya'a, N. (2012). Characteristics of middle school students learning actions in outdoor mathematical activities with the cellular phone. Teaching Mathematics and its Applications: An International Journal of the IMA, 31(3), 133-152. https://doi.org/10.1093/teamat/hrr018

Daher, W., Alfahel, E., \& Anabousy, A. (2021). Moderating the relationship between student's gender and science motivation. EURASIA Journal of Mathematics, Science and Technology Education, 17(5), em1956. https://doi.org/10.29333/ejmste/10829

English, L. D. (2003). Problem posing in the elementary curriculum. In F. Lester \& R. Charles (Eds.), Teaching mathematics through problem solving (pp. 187-198). National Council of Teachers of Mathematics.

Galbraith, P., \& Holton, D. (2018). Mathematical modelling: a guidebook for teachers and teams. Australian Council for Educational Research.

Geiger, V., Faragher, R., \& Goos, M. (2010). CAS-enabled technologies as 'agents provocateurs' in teaching and learning mathematical modeling in secondary school classrooms. Mathematics Education Research Journal, 22(2), 48-68. https://doi.org/10.1007/ BF03217565

Higgins, K., Huscroft-D'Angelo, J., \& Crawford, L. (2019). Effects of technology in mathematics on achievement, motivation, and attitude: A metaanalysis. Journal of Educational Computing Research, 57(2), 283-319. https://doi.org/10.1177/073563311 7748416

Jang, H. (2008). Supporting students' motivation, engagement, and learning during an uninteresting activity. Journal of Educational Psychology, 100(4), 798-811. https:/ / doi.org/10.1037/a0012841

Lewis, G. (2015, February). Patterns of motivation and emotion in mathematics classrooms. In Proceedings of CERME 9-Ninth Congress of the European Society for Research in Mathematics Education (pp. 12161222).

Michaelides, M. P., Brown, G. T., Eklöf, H., \& Papanastasiou, E. C. (2019). The Relationship of Motivation with Achievement in Mathematics. In Motivational Profiles in TIMSS Mathematics (pp. 923). Springer, Cham. https:// doi.org/10.1007/9783-030-26183-2_2

Middleton, J. A., \& Spanias, P. A. (1999). Motivation for achievement in mathematics: Findings, generalizations, and criticisms of the research. Journal for Research in Mathematics Education, 30(1), 65-88. https:// doi.org/10.2307/749630 
Molina-Toro, J. F., Rendón-Mesa, P. A., \& Villa-Ochoa, J. (2019). Research trends in digital technologies and modeling in mathematics education. EURASIA Journal of Mathematics, Science and Technology Education, 15(8), em1736. https:// doi.org/10.29333 /ejmste/108438

Mousoulides, N. G., Christou, C., \& Sriraman, B. (2008). A modeling perspective on the teaching and learning of mathematical problem solving. Mathematical Thinking and Learning, 10(3), 293-304. https:/ / doi.org/10.1080/10986060802218132

Mousoulides, N., Pittalis, M., Christou, C., Boytchev, P., Sriraman, B., \& Pitta, D. (2007). Mathematical modelling using technology in elementary school. In 8th international conference on technology in mathematics teaching, University of Hradec Králové, Czech Republic.

Ntourou, V., Kalogiannakis, M., \& Psycharis, S. (2021). A study of the impact of arduino and visual programming in self-efficacy, motivation, computational thinking and 5th grade students' perceptions on Electricity. EURASIA Journal of Mathematics, Science and Technology Education, 17(5), em1960. https:/ / doi.org/10.29333/ejmste/10842

Patton, M. Q. (2002). Qualitative research and evaluation methods. Sage.

Pekrun, R. (2006). The control-value theory of achievement emotions: Assumptions, corollaries, and implications for educational research and practice. Educational psychology review, 18(4), 315341. https:/ / doi.org/10.1007/s10648-006-9029-9

Rowe, A. D., \& Fitness, J. (2018). Understanding the role of negative emotions in adult learning and achievement: A social functional perspective. Behavioral Sciences, 8(2), 27. https://doi.org/ $10.3390 /$ bs 8020027

Ryan, R. M., \& Deci, E. L. (2000). Intrinsic and extrinsic motivations: Classic definitions and new directions. Contemporary Educational Psychology, 25(1), 54-67. https://doi.org/10.1006/ceps.1999. 1020

Schutz, P. A., Hong, J. Y., Cross, D. I., \& Osbon, J. N. (2006). Reflections on investigating emotion in educational activity settings. Educational Psychology Review, 18(4), 343-360. https://doi.org/10.1007/ s10648-006-9030-3

Shahbari, J. A., \& Peled, I. (2017). Modelling in primary school: Constructing conceptual models and making sense of fractions. International Journal of Science and Mathematics Education, 15(2), 371-391. https: / / doi.org/10.1007/s10763-015-9702-x

Shahbari, J. A., Daher, W., \& Rasslan, S. (2014). Mathematical knowledge and the cognitive and metacognitive processes emerged in modeleliciting activities. International Journal on New Trends in Education and Their Implications, 5(2), 209219.

Shahbari, J. A., Tabach, M., \& Heyd-Metzuyanim, E. (2019). Development of modelling routines and its relation to identity construction. In S. Chamberlin \& B. Sriraman, (Eds.), Affect in Mathematical Modeling (pp 177-199). Springer International Publishing. https:/ / doi.org/10.1007/978-3-030-04432-9_11

Siller, H.-S. \& Greefrath, G. (2010). Mathematical modeling in class regarding to technology. In $\mathrm{V}$. Durand-Guerrier, S. Soury-Lavergne, and F. Arzarello (Eds.), Proceedings of the Sixth Congress of the European Society for Research in Mathematics Education (CERME 6), (pp. 21362145). Lyon, France.

Svebak, S. (1988). A state-based approach to the role of effort in experience of emotions. In V. Hamilton, G. H. Bower, \& N. H. Frijda (eds), Cognitive perspectives on emotion and motivation (pp. 145-171). Kluwer Academic Publishers. https://doi.org/10.1007/ 978-94-009-2792-6_6

Wæge, K. (2010, January). Motivation for learning mathematics in terms of needs and goals. In Proceedings of the Sixth Congress of the European Society for Research in Mathematics Education (Vol. 6, pp. 84-93).

Williams, S. (2011). Engaging and informing students through group work. Psychology Teaching Review, 17(1), 24-34.

\section{http://www.ejmste.com}

